\title{
Consolidation chwemotherapy after concurrent chemoradiotherapy vs. chemoradiotherapy alone for locally advanced unresectable stage III non-small-cell lung cancer: A meta-analysis
}

\author{
XIU-JUN CHANG, ZI-TONG WANG and LEI YANG \\ Department of Thoracic Surgery, Beijing Chest Hospital, Capital Medical University, \\ Beijing Tuberculosis and Tumor Research Institute, Beijing 101149, P.R. China \\ Received January 18, 2016; Accepted May 9, 2016
}

DOI: $10.3892 / \mathrm{mco} .2016 .910$

\begin{abstract}
Concurrent chemoradiotherapy (CCRT) has been considered to be the standard of care for locally advanced unresectable stage III non-small-cell lung cancer (LA-NSCLC). Whether consolidation chemotherapy (CCT) following CCRT is able to further improve the clinical outcome remains unclear. We therefore undertook a meta-analysis to compare the two regimens for LA-NSCLC. A literature search was performed through PubMed, Embase, Cochrane Library and Chinese Biology Medicine, from their inception to November, 2015. Irrelevant studies were excluded using the Preferred Reporting Items for Systematic Reviews and Meta-Analyses standards. Our primary endpoint was overall survival (OS), which was defined as the time from randomisation until death from any cause; the secondary endpoint was progression-free survival (PFS). All analyses were by intention-to-treat. Five phase III randomized controlled trials with 958 patients were included in the present meta-analysis. The results were expressed as odds ratios (ORs) with $95 \%$ confidence intervals (CIs). Compared with CCRT, CCT after CCRT was not associated with statistically significant differences in OS (OR=1.24; 95\% CI: 0.89-1.72; $\mathrm{P}=0.21)$ or PFS (OR=1.16; 95\% CI: $0.74-1.83$; $\mathrm{P}=0.53)$, but increased the risk of toxicity, including infection $(\mathrm{P}=0.02)$, pneumonitis $(\mathrm{P}=0.003)$ and treatment-related death $(\mathrm{P}=0.04)$. There were no significant differences in terms of benefit according to particular patient characteristics, such as age, gender, performance status, tumor histology or clinical stage. Thus, the present study failed to support the use of CCT after CCRT over CCRT alone, as there
\end{abstract}

Correspondence to: Dr Xiu-Jun Chang, Department of Thoracic Surgery, Beijing Chest Hospital, Capital Medical University, Beijing Tuberculosis and Tumor Research Institute, 97 Beimachang Road, Beijing 101149, P.R. China

E-mail: changjun868@sina.com

Key words: non-small-cell lung cancer, chemoradiotherapy, consolidation chemotherapy, locally advanced was no significant OS and PFS benefit for LA-NSCLC patients, but the use of CCT after CCRT resulted in increased toxicity.

\section{Introduction}

Lung cancer remains the leading cause of cancer-related mortality worldwide, with $\sim 1.5$ million new cases diagnosed annually (1). Approximately $87 \%$ of lung cancer patients have non-small cell lung cancer (NSCLC), and approximately one-third of NSCLC patients have locally advanced stage III disease (LA-NSCLC) at the time of diagnosis $(2,3)$. For the treatment of LA-NSCLC, clinical trials have demonstrated that radiation therapy alone is associated with a 5-year survival rate of only $\sim 5 \%(4,5)$. Concurrent chemoradiotherapy (CCRT) was found to result in survival improvement compared with radiation alone (6-8) and sequential CRT (9-15) and is currently the standard treatment for LA-NSCLC. A NSCLC Collaborative Group meta-analysis also demonstrated that CCRT, as compared with sequential CRT, improved the survival of patients with LA-NSCLC (16).

However, for LA-NSCLC patients, the prognosis following CCRT is still poor, with a median survival time of 15-18 months (17). Recently, close attention has been paid to the addition of consolidation chemotherapy (CCT) after CCRT for LA-NSCLC. Previous phase II studies of CCRT followed by $\mathrm{CCT}$ have reported promising response rates and survival results (18-20). In addition, 5 randomized phase III studies were recently reported to evaluate the survival benefit of CCT after CCRT compared with that of CCRT alone (21-25). However, the efficacy of CCT after CCRT in improving survival in LA-NSCLC patients remains controversial. We therefore conducted a meta-analysis of published phase III randomized controlled trials (RCTs) to quantitatively evaluate the survival benefit of patients who received the two regimens.

\section{Materials and methods}

Eligibility criteria. CCRT was defined as chemotherapy administered during radiotherapy. Radiation should be similar in both arms of the trial. CCRT followed by CCT was defined as chemotherapy administered after CCRT. RCTs comparing 
CCT after CCRT with CCRT alone were conducted, using the Preferred Reporting Items for Systematic Reviews and Meta-Analyses standards (26) as the basis for reporting the materials and methods of this study. The following eligibility criteria for this meta-analysis were set prior to collecting the articles: i) Phase III RCTs; ii) studies involving patients with stage III locally advanced NSCLC based upon international staging criteria (27); iii) hazard ratios (HRs) and confidence intervals (CIs) of the patients who received CCRT and CCRT followed by CCT should be calculated at specific time intervals after therapy from the survival rates in the article; iv) the median follow-up time of the study should be $\geq 3$ years.

Data collection. Published and unpublished trials were sought by searching electronic databases (PubMed, Embase, Cochrane Library and Chinese Biology Medicine) without language restriction, using the Cochrane collaboration optimal search strategy for identifying RCTs. This was supplemented by manual searches. Two investigators independently searched eligible trials and discrepancies were resolved through discussion. Non-English publications were evaluated upon their English abstract and the translation of their main text. Using the keywords "concurrent chemoradiotherapy + consolidation chemotherapy + non-small cell lung cancer', 365 citations were identified in total. Unrelated articles were excluded and, finally, only 5 studies (21-25) fulfilled all our eligibility criteria. Study characteristics were also recorded (period during which the study was conducted, chemoradiotherapy regimen and median follow-up) and patient characteristics [age, gender, cancer stage, performance status (PS), forced expiratory volume in 1 second (FEV1) and toxicity].

Validity assessment. Two reviewers independently evaluated the quality of the studies, with disagreements resolved by consensus. Using the Cochrane approach to allocation concealment, the trials were described as having adequate, unclear, or inadequate concealment (28). The reviewers assessed whether there was blinding of outcome assessment and adequate description of withdrawals (29). The adequacy of the method of randomization was assessed as described by Jadad et al (29). Finally, an assessment was made as to whether the trial results used intention-to-treat analysis $(30,31)$. The authors of the included studies were asked to verify the assessments of study methodology where possible.

Statistical analysis. The primary endpoint was overall survival (OS), which was defined as the time from randomisation until death from any cause. The secondary endpoints were acute toxicity rates and progression-free survival (PFS), which was defined as the time from random assignment until first event (local or distant progression or death from any cause). Surviving patients were censored at the date of the last follow-up. The survival rates were derived from the published survival curves when not provided explicitly in the text or tables. Data extraction from the survival curves was independently performed by two researchers, and the mean measured values were used for the meta-analysis.

Statistical analyses for the meta-analysis were performed with Review Manager software for Windows, version 5.3 (Cochrane Collaboration, Oxford, UK, 2014) and a pooled relative risk was calculated with $95 \%$ CIs. Analyses were stratified by trials. The log-rank test was used to estimate the observed and expected number of events and associated variances were used to calculate individual trial and overall combined odds ratios (ORs) and their 95\% CIs by the fixed-effects model. To undertake a random-effects meta-analysis, the standard errors of the study-specific estimates are adjusted to incorporate a measure of the extent of variation, or heterogeneity, among the treatment effects observed in different studies. Chi-quare $\left(\chi^{2}\right)$ heterogeneity tests were used to test for statistical heterogeneity among trials. The $\mathrm{I}^{2}$ statistics were also used to assess the proportion of variability in the results attributable to heterogeneity across studies; $\mathrm{I}^{2}<25 \%, \mathrm{I}^{2}$ of $\geq 25 \%$ but $<50 \%$, and $\mathrm{I}^{2} \geq 50 \%$ were interpreted as indicating low-level, intermediate-level and high-level heterogeneity, respectively (28). Analyses by patient characteristics were performed to study the interaction between the treatment effect and the following characteristics: Gender, age, PS, FEV1, stage and toxicities. All P-values were two-sided. $\mathrm{P}<0.05$ was considered to indicate statistically significant differences.

\section{Results}

Study characteristics. We identified 5 randomized phase III studies (21-25) including 958 patients, which investigated the survival of LA-NSCLC patients treated with CCRT followed by CCT (Fig. 1). All 5 studies reported mature data on survival benefit and toxicity, whereas 3 studies were reported as meeting abstracts $(21,23,24)$. In 2 of these 3 trials $(21,23)$, patients lacked specific OS and PFS; thus, their survival rates were not included in our meta-analysis, but the patient characteristics in those 2 trials are available. Our meta-analysis on OS and PFS was only based on 3 trials with 768 patients who were randomly assigned. The analyses of patient characteristics were based on all 5 trials and 958 patients.

Treatment regimens. Two trials $(21,23)$ used the same chemotherapy regimen in both arms. In 1 trial (21), induction chemotherapy with paclitaxel $200 \mathrm{mg} / \mathrm{cm}^{2}$ was used prior to CCRT followed by CCT. Paclitaxel $\left(45 \mathrm{mg} / \mathrm{m}^{2}\right)$ and carboplatin (area under the curve $=2$ ) were used as CCRT in another study (23). Another 3 trials $(22,24,25)$ used cisplatin combined with one other drug (etoposide, docetaxel or vinorelbine). All the trials used a two-dimensional radiation technique as CCRT; the total dose was $66 \mathrm{~Gy}$ in 4 trials and $59.4 \mathrm{~Gy}$ in 1 trial (22). In the 3 trials $(22,23,25), 3$ cycles of CCT were scheduled, using the same chemotherapy regimen as CCRT. In another 2 trials $(21,24) 7$ and 2 cycles of CCT were delivered accordingly. The trial characteristics are summarized in Table I. There was no significant difference between the two treatments according to particular patient characteristics, such as age, gender, PS, histology, or clinical stage, in terms of benefit (Table II).

Study quality. The quality of the included trials is shown in Table III. All the included studies were found to have an unclear allocation concealment, but they were conducted with a method of adequate randomization and with intention-to-treat analysis. One trial clearly pointed out blinded assessment of 


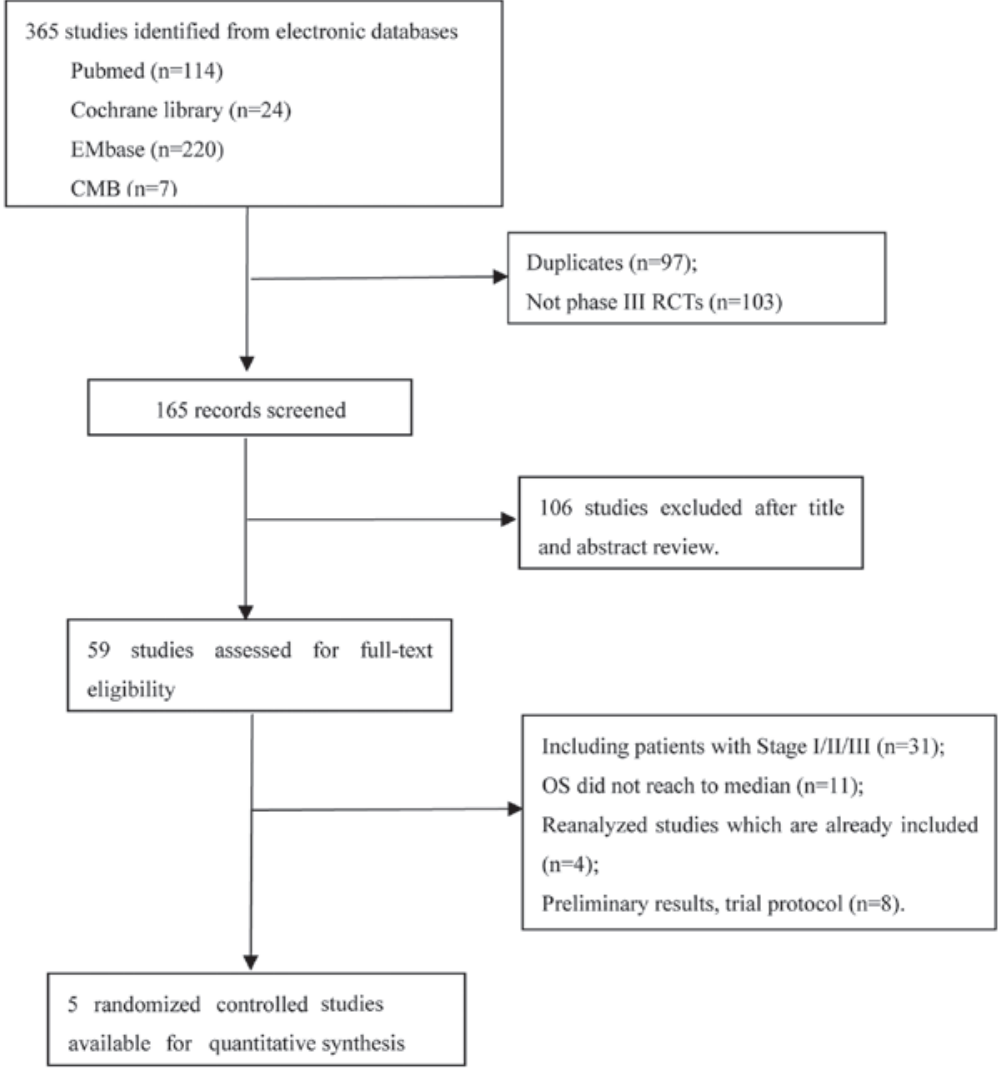

Figure 1. Flow diagram of studies included in systematic review and meta-analysis. RCTs, randomized controlled trials.

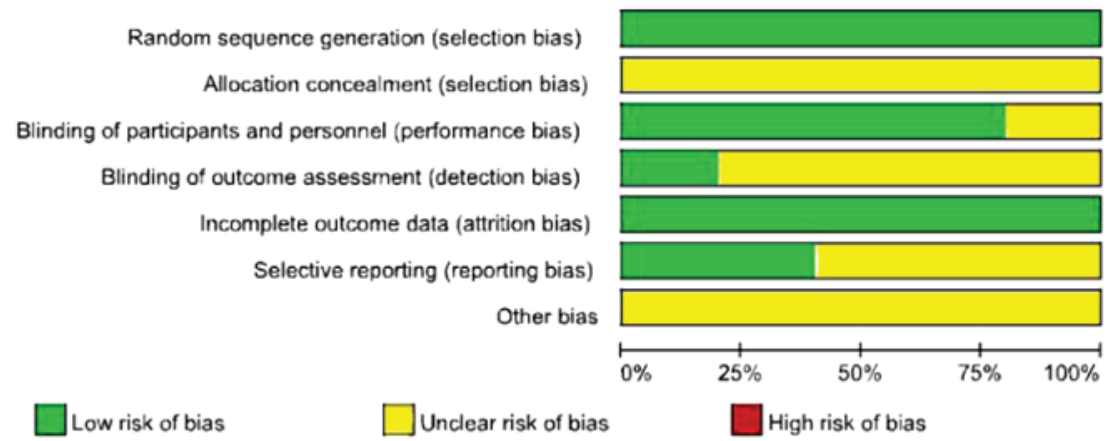

Figure 2. Risk of bias graph: Review of authors' assessment on each risk of bias item presented as percentages across all included studies.

outcome (22), whereas the remaining 4 trials did not describe the assessment method of outcome. According to the methodological quality of 3 trials, we reviewed the authors' judgement regarding each risk of bias item (Fig. 2).

Survival analysis. The survival analysis was based on 3 trials with 768 patients. CCRT followed by CCT failed to result in significant improvement in terms of 4-year $\mathrm{OS}(\mathrm{OR}=1.24$; 95\% CI: 0.89-1.72; P=0.21) compared with CCRT alone (Fig. 3). There was no evidence of significant statistical heterogeneity with an $\mathrm{I}^{2}$ value of $7 \%\left(\chi^{2}\right.$ test for heterogeneity $\mathrm{P}=0.34)$. The PFS analysis was based on 2 trials including 567 patients. CCRT followed by CCT did not improve 3 -year PFS (OR=1.16; 95\% CI: 0.74-1.83; $\mathrm{P}=0.53$ ) compared with CCRT alone (Fig. 4). There was no evidence of significant statistical heterogeneity, with an $\mathrm{I}^{2}$ value of $0 \%\left(\chi^{2}\right.$ test for heterogeneity $\mathrm{P}=0.52)$. Data were available for 491 patients $(51 \%)$ for infection $(\mathrm{P}=0.02)$, peumonitis $(\mathrm{P}=0.003)$ and treatment-related death $(\mathrm{P}=0.04)$. Esophageal toxicity was analyzed by only 1 available trial (25) due to sparsity of data $(\mathrm{P}=0.09)$ (Table II).

\section{Discussion}

Despite the advances in the treatments for LA-NSCLC, the multidisciplinary approach for the management of LA-NSCLC remains controversial among clinicians. On the basis of large clinical trials (6-15), the treatment of choice for stage III unresectable NSCLC is CCRT. However, the main benefit of CCRT is likely to be due to decreased locoregional progression, rather than distant progression control and decreased acute toxicities (16). Recently, clinical trials on CCRT followed by 


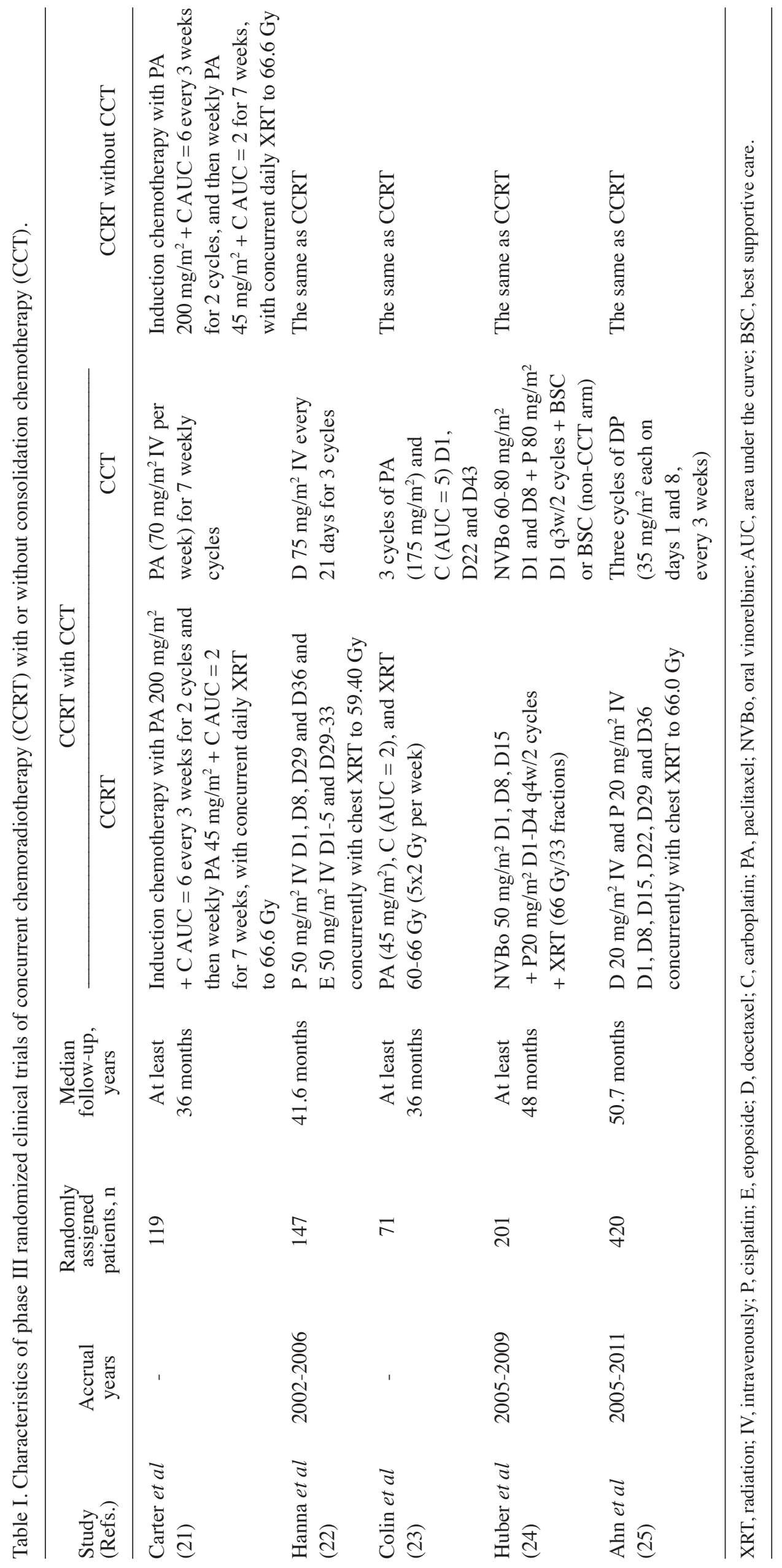


Table II. Patient characteristics.

\begin{tabular}{|c|c|c|c|c|c|}
\hline \multirow[b]{2}{*}{ Characteristics } & \multicolumn{2}{|c|}{ CCT after CCRT } & \multicolumn{2}{|c|}{ CCRT } & \multirow[b]{2}{*}{ P-value } \\
\hline & No. & $\%$ & No. & $\%$ & \\
\hline Median age, years & \multicolumn{2}{|c|}{61} & \multicolumn{2}{|c|}{61} & - \\
\hline Range & \multicolumn{2}{|c|}{$31-86$} & \multicolumn{2}{|c|}{$33-86$} & - \\
\hline Gender (female) & 92 & 24.3 & 82 & 21.0 & 0.27 \\
\hline \multicolumn{6}{|l|}{ Performance status } \\
\hline 0 & 90 & 31.9 & 95 & 33.5 & 0.72 \\
\hline$\geq 1.0$ & 191 & 67.7 & 190 & 66.7 & 0.79 \\
\hline \multicolumn{6}{|l|}{ FEV1, 1} \\
\hline 0.8 to $<2.0$ & 113 & 40.0 & 93 & 32.6 & 0.07 \\
\hline$\geq 2.0$ & 169 & 59.9 & 192 & 67.4 & 0.07 \\
\hline \multicolumn{6}{|l|}{ Stage } \\
\hline IIIA & 91 & 24.1 & 102 & 26.2 & 0.51 \\
\hline IIIB & 286 & 75.7 & 287 & 73.6 & 0.51 \\
\hline \multicolumn{6}{|l|}{ Toxicity } \\
\hline Infection & 23 & 9.4 & 10 & 4.1 & 0.02 \\
\hline Pneumonitis & 30 & 12.2 & 11 & 4.5 & 0.003 \\
\hline Treatment-related death & 9 & 3.7 & 0 & 0.0 & 0.04 \\
\hline Esophagitis & 61 & 35.3 & 46 & 26.9 & 0.09 \\
\hline
\end{tabular}

Percentages were calculated on known values. CCT, consolidation chemotherapy; CCRT, concurrent chemoradiotherapy; FEV1, forced expiratory volume in $1 \mathrm{sec}$.

Table III. Methodological quality of included trials.

\begin{tabular}{|c|c|c|c|c|c|}
\hline Study (Refs.) & $\begin{array}{l}\text { Allocation } \\
\text { concealment }\end{array}$ & $\begin{array}{l}\text { Method of } \\
\text { randomization }\end{array}$ & $\begin{array}{c}\text { Blinded assessment } \\
\text { of outcome }\end{array}$ & $\begin{array}{l}\text { Description of } \\
\text { withdrawals }\end{array}$ & $\begin{array}{c}\text { Intention to treat } \\
\text { analysis }\end{array}$ \\
\hline Carter et al (21) & Unclear & Adequate & None described & Yes & Yes \\
\hline Hanna et al (22) & Unclear & Adequate & Yes & Yes & Yes \\
\hline Colin tal (23) & Unclear & Adequate & None described & Yes & Yes \\
\hline Huber et al (24) & Unclear & Adequate & None described & Yes & Yes \\
\hline Ahn et al (25) & Unclear & Adequate & None described & Yes & Yes \\
\hline
\end{tabular}

CCT (18-25) or induction treatment followed by CCRT (32-34) have became progressively more popular in an attempt to improve distant disease control. However, there is no clear evidence in terms of conferring survival benefits compared with the current standard CCRT for LA-NSCLC patients. Against this background, we conducted a meta-analysis to evaluate the efficacy and toxicity of CCRT followed by CCT vs. CCRT alone in the treatment of LA-NSCLC.

To the best of our knowledge, ours is the first meta-analysis of CCRT followed by CCT compared with CCRT alone, including 5 complete phase III RCTs. Although a pooled analysis performed by Tsujino et al (35) demonstrated the inefficiency of CCT after CCRT for LA-NSCLC, their subsequent letters to the editor (36) pointed out several limitations that may have affected their study results. First, the authors failed to assess the heterogeneity at the individual patient level, indicating that they did not analyze the specific characteristics of the patients. In addition, the diversity of the CCT regimens among trials is another important factor that may affect their study results. Two patterns were included: Continuous CCT, which continues the same chemotherapy as CCRT, and switch CCT, which changes to different agents in the consolidation phase. However, in our meta-analysis, we overcame these limitations by selecting complete phase III RCTs with specific patient characteristics. In addition, the trials included only investigated continuous CCT, suggesting that our study significantly decreased publication bias.

Our meta-analysis revealed no significant survival benefit in terms of $\mathrm{OS}(\mathrm{OR}=1.24 ; 95 \% \mathrm{CI}$ : 0.89-1.72; $\mathrm{P}=0.21)$ and $\mathrm{PFS}$ $(\mathrm{OR}=1.16$; 95\% CI: 0.74-1.83; $\mathrm{P}=0.53)$ for CCRT followed by CCT compared with CCRT alone. In accordance with the results from the 5 included phase III RCTs, the difference in OS and PFS was not significant between patients receiving CCRT followed by CCT and those receiving CCRT alone. In 


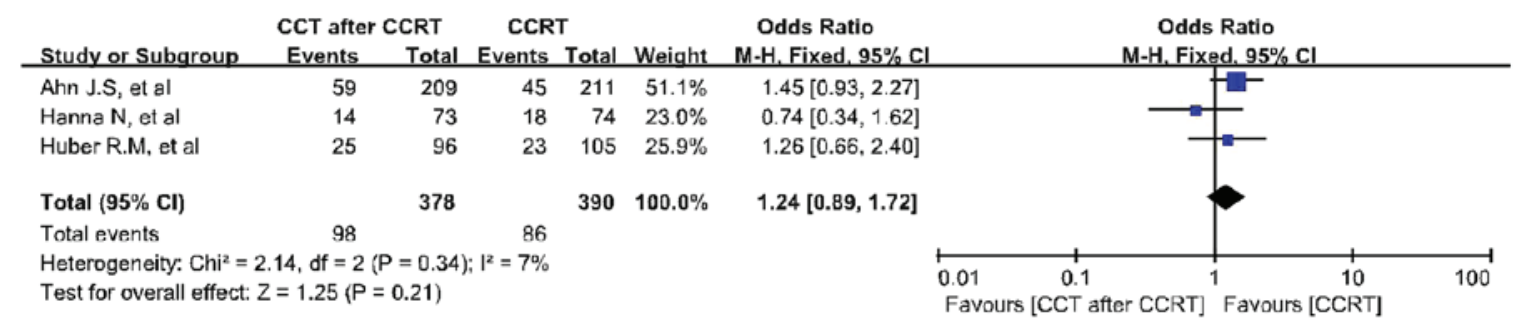

Figure 3. 4-year overall survival. CCT, consolidation chemotherapy; CCRT, concurrent chemoradiotherapy; CI, confidence interval; df, degree of freedom.

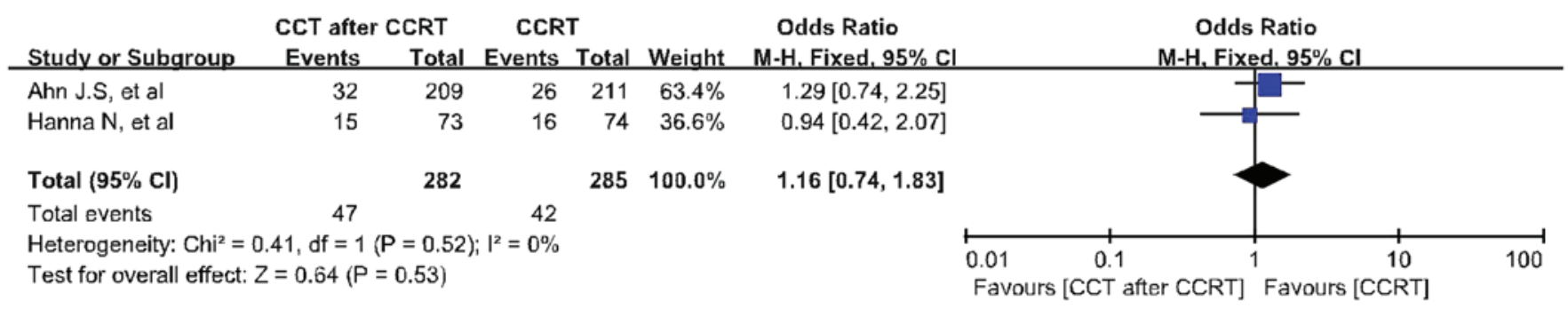

Figure 4. Three-year progression-free survival. CCT, consolidation chemotherapy; CCRT, concurrent chemoradiotherapy; CI, confidence interval; df, degree of freedom.

addition, the OS and PFS synthesis included 3 trials $(22,24,25)$, which were based on cisplatin combined with one other drug as chemotherapeutic agents, and used almost the same radiation technique and doses for treatment. This way, treatment heterogeneity may be lowered to the minimum degree. Collectively, our meta-analysis provided clinicians with highly persuasive evidence that the survival benefit of CCT after CCRT is moderate. Moreover, Kelly et al (37) conducted a progressive phase III trial of maintenance gefitinib or placebo after CCRT and docetaxel cosolidation in inoperable stage III NSCLC. Although treatment with epidermal growth factor receptor-tyrosine kinase inhibitors as maintenance after CCT was delivered to the patients, gefitinib still failed to improve distant progression and survival, suggesting that the concept of CCT requires further investigation. However, a number of oncologists still treat LA-NSCLC patients with CCT after CCRT. It appears that clinicians reached a plateau in survival benefit using the current treatment (CCRT followed by CCT as well as CCRT alone) against stage III NSCLC.

With regards to our meta-analysis, we noted significant differences in toxicities, such as infection $(\mathrm{P}=0.02)$, pneumonitis $(\mathrm{P}=0.003)$ and treatment-related death $(\mathrm{P}=0.04)$. By contrast, the pooled analysis (35) indicated that no difference was observed in toxicity between the two groups, mainly as several included studies were phase I/II clinical trials without sufficient available toxicity data. Our meta-analysis included all phase III RCTs with specific data, so that we were able to analyze the differences in toxicity between patients who received CCT after CCRT and those who received CCRT alone. Schild et al (38) reported that older patients experienced higher rates of grade 4 toxicity (81 vs. $62 \%$, $\mathrm{P}=0.007)$, hematological toxicity (78 vs. $56 \%, \mathrm{P}=0.003$ ) and pneumonitis (6 vs. $1 \%, \mathrm{P}=0.02$ ). Additionally, based on the HOG LUN 01-24 phase III trial (22), Jalal et al (39) published undated survival and outcome data that also support grade 3 and 4 toxicity noted during the induction and consolidation phases of the trial, particularly for patients aged $\geq 70$ years vs. younger patients ( 87 vs. $73 \%$, respectively; $\mathrm{P}=0.02$ ). However, KCSG-LU05-04 (25) reported a significant benefit with CCT after CCRT in patients aged $>60$ years, suggesting that a more gradual strategy may be more appropriate for the elderly population. This results were consistent with a population-based study from the National Cancer Institute's Surveillance, Epidemiology and End Results database (40). There are two possible reasons for this discrepancy: First, for CCT after CCRT, several patients were unable to complete all the CCT cycles; thus, we could not exclude the possibility that the patients who did complete CCT after CCRT were aged $\geq 60$ years. Furthermore, although the radiation was delivered under the same conditions, cisplatin combined with weekly docetaxel as second-line chemotherapy may be superior to the first-line chemotherapy due to the acceptable toxicity profile. In addition, several phase III trials and a meta-analysis demonstrated a significant benefit in grade 3-4 neutropenia compared with docetaxel every 3 weeks (41-44).

There were two limitations in this meta-analysis. First, since we included published trials, our analysis may include heterogeneous studies. For example, eligible patients were not selected based on rigid inclusion criteria. A number of patients who were unable to complete all the cycles of CCT after CCRT were included in the analysis. Second, 3 abstract meetings were included in our analysis, for which not all survival data were available; our meta-analysis may be updated following publication of their specific data.

On the basis of our meta-analysis, CCT after CCRT, as compared with CCRT alone, failed to improve the OS and PFS rates; in addition, CCT after CCRT was associated with increased toxicity. Thus, further clinical trials are warranted to seek novel breakthrough treatment options to improve the prognosis of patients with LA-NSCLC. 


\section{References}

1. Jemal A, Bray F, Center MM, Ferlay J, Ward E and Forman D: Global cancer statistics. CA Cancer J Clin 61: 69-90, 2011.

2. American Cancer Society: Cancer facts and figures 2007. Atlanta: American Cancer Society, 2007.

3. Goldstraw P, Crowley J, Chansky K, Giroux DJ, Groome PA, Rami-Porta R, Postmus PE, Rusch V and Sobin L; International Association for the Study of Lung Cancer International Staging Committee; Participating Institutions: The IASLC Lung Cancer Staging Project: Proposals for the revision of the TNM stage groupings in the forthcoming (seventh) edition of the TNM Classification of Malignant Tumours. J Thorac Oncol 2: 706-714, 2007.

4. Perez CA, Pajak TF, Rubin P, Simpson JR, Mohiuddin M, Brady LW, Perez-Tamayo R and Rotman M: Long-term observations of the patterns of failure in patients with unresectable non-oat cell carcinoma of the lung treated with definitive radiotherapy. Report by the Radiation Therapy Oncology Group Cancer 59: 1874-1881, 1987.

5. Jonhnson DH, Einhorn LH, Bartolucci A, Birch R, Omura G, Perez CA and Greco FA: Thoracic radiotherapy does not prolong survival in patients with locally advanced, unresectable non-small cell lung cancer. Ann Intern Med 113: 33-38, 1990.

6. Dillman RO, Herndon J, Seagren SL, Eaton WL Jr and Green MR: Improved survival in stage III non-small-cell lung cancer: Seven-year follow-up of Cancer and Leukemia Group B (CALGB) 8433 trial. J Natl Cancer Inst 88: 1210-1215, 1996.

7. Schaake-Koning C, van den Bogaert W, Dalesio O, Festen J, Hoogenhout J, van Houtte P, Kirkpatrick A, Koolen M, Maat B, Nijs A, et al: Effects of concomitant cisplatin and radiotherapy on inoperable non-small-cell lung cancer. N Engl J Med 326: 524-530, 1992.

8. Sause W, Kolesar P, Taylor S IV, Johnson D, Livingston R, Komaki R, Emami B, Curran W Jr, Byhardt R, Dar AR and Turrisi A III: Final results of phase III trial in regionally advanced unresectable non-small cell lung cancer: Radiation Therapy Oncology Group, Eastern Cooperative Oncology Group and Southwest Oncology Group. Chest 117: 358-364, 2000.

9. Clamon G, Herndon J, Eaton W, Rosenman J, Maurer LH, Cooper MR and Green MR: A feasibility study of extended chemotherapy for locally advanced non-small cell lung cancer: A phase II trial of Cancer and Leukemia Group B. Can Invest 12: 273-282, 1994

10. Furuse K, Fukuoka M, Kawahara M, Nishikawa H, Takada Y Kudoh S, Katagami N and Ariyoshi Y: Phase III study of concurrent versus sequential thoracic radiotherapy in combination with mitomycin, vindesine, and cisplatin in unresectable stage III non-small cell lung cancer. J Clin Oncol 17: 2692-2699, 1999.

11. Curran WJ, Scott CB, Langer CJ, et al: Long-term benefit is observed in a phase III comparison of sequential versus concurrent chemo-radiation forpatients with unresected stage III NSCLC: RTOG 9410. Proc Am Soc Clin Oncol 22: $621,2003$.

12. Ulutin HC, Güden M, Oysul K, Sürenkök S and Pak Y: Split-course radiotherapy with or without concurrent or sequential chemotherapy in non-small cell lung cancer. Radiat Med 18: 93-96, 2000.

13. Fournel P, Robinet G, Thomas P, Souquet PJ, Léna H, Vergnenégre A, Delhoume JY, Le Treut J, Silvani JA, Dansin E, et al: Randomized phase III trial of sequential chemoradiotherapy compared with concurrent chemoradiotherapy in locally advanced non-small-cell lung cancer: Groupe Lyon-Saint-Etienne d'Oncologie Thoracique-Groupe Francais de Pneumo-Cancérologie NPC 95-01 study. J Clin Oncol 23: 5910-5917, 2005.

14. Zatloukal P, Petruzelka L, Zemanova M, Havel L, Janku F, Judas L, Kubik A, Krepela E, Fiala P and Pecen L: Concurrent versus sequential chemoradiotherapy with cisplatin and vinorelbine in locally advanced non-small cell lung cancer: A randomized study. Lung Cancer 46: 87-98, 2004.

15. Belderbos J, Uitterhoeve L, van Zandwijk N, Belderbos $H$, Rodrigus P, van de Vaart P, Price A, van Walree N, Legrand C, Dussenne $\mathrm{S}$, et al: Randomised trial of sequential versus concurrent chemo-radiotherapy in patients with inoperable non-small cell lung cancer (EORTC 08972-22973). Eur J Cancer 43: 114-121, 2007.
16. Aupérin A, Péchoux CL, Rolland E, Curran WJ, Furuse K, Fournel P, Belderbos J, Clamon G, Ulutin HC, Paulus R, et al: Meta-analysis of concomitant versus sequential radiochemotherapy in locally advanced non-small-cell lung cancer. J Clin Oncol 28: 2181-2190, 2010.

17. Aupérin A, Le Péchoux C, Pignon JP, Koning C, Jeremic B, Clamon G, Einhorn L, Ball D, Trovo MG, Groen HJ, et al: Concomitant radio-chemotherapy based on platin compounds in patients with locally advanced non-small cell lung cancer (NSCLC): A meta-analysis of individual data from 1764 patients. Ann Oncol 17: 473-483, 2006.

18. Davies AM, Chansky K, Lau DH, Leigh BR, Gaspar LE, Weiss GR, Wozniak AJ, Crowley JJ and Gandara DR; SWOG S9712: Phase II study of consolidation paclitaxel after concurrent chemoradiation in poor-risk stage III non-small-cell lung cancer: SWOG S9712. J Clin Oncol 24: 5242-5246, 2006.

19. Edelman MJ, Chansky K, Gaspar LE, Leigh B, Weiss GR, Taylor SA, Crowley J, Livingston R and Gandara DR: Phase II trial of cisplatin/etoposide and concurrent radiotherapy followed by paclitaxel/carboplatin consolidation for limited small-cell lung cancer: Southwest Oncology Group 9713. J Clin Oncol 22: 127-132, 2004.

20. Sakai H, Yoneda S, Kobayashi K, Komagata H, Kosaihira S, Kazumoto T and Saito Y: Phase II study of bi-weekly docetaxel and carboplatin with concurrent thoracic radiation therapy followed by consolidation chemotherapy with docetaxel plus carboplatin for stage III unresectable non-small cell lung cancer. Lung Cancer 43: 195-201, 2004.

21. Carter DL, Keller AM, Tolley RC, et al: A randomized phase III trial of combined paclitaxel, carboplatin and radiation therapy followed by either weekly paclitaxel or observation in patients with stage III non-small cell lung cancer. J Clin Oncol 20 (suppl, abstr 7076): 15s, 2004.

22. Hanna N, Neubauer M, Yiannoutsos C, McGarry R, Arseneau J, Ansari R, Reynolds C, Govindan R, Melnyk A, Fisher W, et al: Phase III study of cisplatin, etoposide, and concurrent chest radiation with or without consolidation docetaxel in patients with inoperable stage III non-small-cell lung cancer: The Hoosier Oncology Group and US Oncology. J Clin Oncol 26: 5755-5760, 2008.

23. Colin P, Jovenin N, Ganem G, et al: Effect of paclitaxel-carboplatin (PC) consolidation chemotherapy after weekly PC concurrent chemo-radiotherapy (CCR) for patients with locally advanced non-small cell lung cancer (LA-NSCLC): 3-year definitive results of the B001-phase III GERCOR-study. J Clin Oncol; 24 (suppl, abstr 7112): 18s, 2006.

24. Huber RM, Engel-Riedel W, Kollmeier J, et al: GILT study: Oral vinorelbine $(\mathrm{NVBo})$ and cisplatin $(\mathrm{P})$ with concomitant radiotherapy (RT) followed by either consolidation (C) with NVBo plus $\mathrm{P}$ plus best supportive care (BSC) or BSC alone in stage (st) III non-small cell lung cancer (NSCLC): Final results of a phase (ph) III study. J Clin Oncol 30: 452s (suppl, abstr 7001), 2012.

25. Ahn JS, Ahn YC, Kim JH, Lee CG, Cho EK, Lee KC, Chen M, Kim DW, Kim HK, Min YJ, et al: Multinational randomized phase III trial with or without consolidation chemotherapy using docetaxel and cisplatin after concurrent chemoradiation in inoperable stage III non-small-cell lung cancer: KCSG-LU05-04. J Clin Oncol 33: 2660-2666, 2015.

26. Liberati A, Altman DG, Tetzlaff J, Mulrow C, Gøtzsche PC, Ioannidis JP, Clarke M, Devereaux PJ, Kleijnen J and Moher D: The PRISMA statement for reporting systematic reviews and meta-analyses of studies that evaluate health care interventions: Explanation and elaboration. PLoS Med 6: e1000100, 2009.

27. Rami-Porta R, Crowley JJ and Goldstraw P: The revised TNM staging system for lung cancer. Ann Thorac Cardiovasc Surg 15: 4-9, 2009 .

28. Higgins JP and Green S: Cochrane Handbook for Systematic Reviews of Interventions Version 5.1.0 (updated March 2011). The Cochrane Collaboration, 2011. Available from www. Cochrane-handbook.Org.

29. Jadad A, Moore RA, Carroll D, Jenkinson C, Reynolds DJ, Gavaghan DJ and McQuay HJ: Assessing the quality of reports of randomized clinical trials: Is blinding necessary? Control Clin Trials 17: 1-12, 1996

30. Montori $\mathrm{V}$ and Guyatt GH: Intention-to-treat principle. CMAJ 165: 1339-1341, 2001

31. Fergusson D, Aaron SD, Guyatt G and Hébert P: Post-randomisation exclusions: The intention to treat principle and excluding patients from analysis. BMJ 325: 652-654, 2002. 
32. Liu D, Zheng X, Chen J, Liu G, Xu Y, Shen Y, Xie L, Zhao W, Jiang $G$ and Fan M: Induction chemotherapy with cetuximab, vinorelbine-cisplatin followed by thoracic radiotherapy and concurrent cetuximab, vinorelbine-cisplatin in patients with unresectable stage III non-small cell lung cancer. Lung Cancer 89: 249-254, 2015.

33. Vokes EE, Herndon JE II, Kelley MJ, Cicchetti MG, Ramnath N, Neill H, Atkins JN, Watson DM, Akerley W and Green MR; Cancer and Leukemia Group B: Induction chemotherapy followed by chemoradiotherapy compared with chemoradiotherapy alone for regionally advanced unresectable stage III Non-small-cell lung cancer: Cancer and Leukemia Group B. J Clin Oncol 25: 1698-1704, 2007.

34. Divers SG, Spencer SA, Carey D, Busby EM, Hyatt MD and Robert F: Phase I/IIa study of cisplatin and gemcitabine as induction chemotherapy followed by concurrent chemoradiotherapy with gemcitabine and paclitaxel for locally advanced non-small-cell lung cancer. J Clin Oncol 23: 6664-6673, 2005.

35. Tsujino K, Kurata T, Yamamoto S, Kawaguchi T, Kubo A, Isa S, Hasegawa Y, Ou SH, Takada M and Ando M: Is consolidation chemotherapy after concurrent chemo-radiotherapy beneficial for patients with locally advanced non-small-cell lung cancer? A pooled analysis of the literature. J Thorac Oncol 8: 1181-1189, 2013.

36. Tsujino K, Kurata T, Kawaquchi T, Kubo A, Takada M and Ando M: Role of consolidation chemotherapy after concurrent chemo-radiotherapy in locally advanced non-small-cell lung cancer. J Thorac Oncol 9: e7-e8, 2014.

37. Kelly K, Chansky K, Gaspar LE, Albain KS, Jett J, Ung YC, Lau DH, Crowley JJ and Gandara DR: Phase III trial of maintenance gefitinib or placebo after concurrent chemoradiotherapy and docetaxel consolidation in inoperable stage III non-small-cel lung cancer: SWOG S0023. J Clin Oncol 26: 2450-2456, 2008.

38. Schild SE, Stella PJ, Geyer SM, Bonner JA, McGinnis WL, Mailliard JA, Brindle J, Jatoi A and Jett JR; North Central Cancer Treatment Group: The outcome of combined-modality therapy for stage III non-small-cell lung cancer in the elderly. J Clin Oncol 21: 3201-3206, 2003.
39. Jalal SI, Riggs HD, Melnyk A, Richards D, Agarwala A, Neubauer M, Ansari R, Govindan R, Bruetman D, Fisher W, et al: Updated survival and outcomes for older adults with inoperable stage III non-small-cell lung cancer treated with cisplatin, etoposide, and concurrent chest radiation with or without consolidation docetaxel: Analysis of a phase III trial from the Hoosier Oncology Group (HOG) and US Oncology. Ann Oncol 23: 1730-1738, 2012

40. Davidoff AJ, Gardner JF, Seal B and Edelman MJ: Population-based estimates of survival benefit associated with combined modality therapy in elderly patients with locally advanced non-small cell lung cancer. J Thorac Oncol 6: 934-941, 2011.

41. Bria E, Cuppone F, Ciccarese M, Nisticò C, Facciolo F, Milella M, Izzo F, Terzoli E, Cognetti F and Giannarelli D: Weekly docetaxel as second line chemotherapy for advanced non-small-cell lung cancer: Meta-analysis of randomized trials. Cancer Treat Rev 32: 583-587, 2006

42. Camps C, Massuti B, Jiménez A, Maestu I, Gómez RG, Isla D, González JL, Almenar D, Blasco A, Rosell R, et al: Randomized phase III study of 3-weekly versus weekly docetaxel in pretreated advanced non-small-cell lung cancer: A Spanish Lung Cancer Group trial. Ann Oncol 17: 467-472, 2006.

43. Gridelli C, Gallo C, Di Maio M, Barletta E, Illiano A, Maione P, Salvagni S, Piantedosi FV, Palazzolo G, Caffo O, et al: A randomised clinical trial of two docetaxel regimens (weekly vs 3 week) in the second-line treatment of non-small-cell lung cancer. The DISTAL 01 study. Br J Cancer 91: 1996-2004, 2004.

44. Schuette W, Nagel S, Blankenburg T, Lautenschlaeger C, Hans K, Schmidt EW, Dittrich I, Schweisfurth H, von Weikersthal LF, Raghavachar A, et al: Phase III study of second-line chemotherapy for advanced non-small-cell lung cancer with weekly compared with 3-weekly docetaxel. J Clin Oncol 23: 8389-8395, 2005. 